\title{
Study of Cardiac Manifestations in Dengue Fever
}

\author{
Arati Kalakutakar ${ }^{1}$, H. Suresh ${ }^{2}$ and G. Ashok ${ }^{3 *}$ \\ ${ }^{1}$ Department of Microbiology, KIMS Hubli, India \\ ${ }^{2}$ Department of Cardiology, KIMS Hubli, India \\ ${ }^{3}$ Department of Medicine, KIMS Hubli, India \\ *Corresponding author
}

\section{A B S T R A C T}

Dengue fever is an acute febrile infectious disease, caused by any of four serotypes. Severe dengue infections may give rise to many complications such as liver failure, disseminated intravascular coagulation, encephalopathy, myocarditis, acute renal failure and haemolytic uraemic syndrome. ST segment and $\mathrm{T}$ wave changes in the electrocardiogram together with low ejection fraction and global hypokinesia on radionuclide ventriculography have been found. Hence, this study was intended to assess the cardiac manifestations in dengue fever patients. To determine the clinical profile of Dengue patients in the study and to

\section{Keywords}

Dengue fever, Cardiac manifestations

Article Info

Accepted: 07 June 2019 Available Online: 10 July 2019
Study the cardiac manifestations in patients with dengue fever. This study was a hospital based study conducted in Karnataka Institute of Medical Sciences, Hubli. Universal Sample size was taken in the study. I.e. all the cases of Dengue Fever admitted to KIMS Hospital, Hubli for the period of $1 \frac{1}{2}$ year. All the cases which satisfy the inclusion criteria were included in the study. Informed consent was taken and the clinical and laboratory parameters were recorded in predesigned data sheet. Diagnosis and management were done according to WHO guidelines. Serological tests for detection of $\operatorname{IgM}$ dengue antibodies and NS1 antigen was done. All the subjects were subjects for laboratory investigations. Data was entered into Microsoft excel data sheet and was analyzed using SPSS 22 version software. $p$ value (Probability that the result is true) of $<0.05$ was considered as statistically significant after assuming all the rules of statistical tests. CK$\mathrm{MB}$ and Troponin I at admission were raised in $18 \%$ and $72 \%$ respectively. On ECG, $56 \%$ of the patients had normal rhythm, $15 \%$ had sinus Bradycardia, $9 \%$ had sinus tachycardia, $10 \%$ had $\mathrm{T}$ wave changes, $3 \%$ had ST Changes, $2 \%$ had Sinus Bradycardia with T Wave Changes, $2 \%$ had Sinus Tachycardia with $\mathrm{T}$ wave changes and $1 \%$ had LVH and $2 \%$ had Abnormal Rhythm. From this study we can conclude that cardiac manifestations cause significant morbidity and in our study no mortality occurred. Hence cardiac manifestations are important in the management and assessing the prognosis of the patients with dengue.

\section{Introduction}

Dengue Fever an acute febrile infectious disease, caused by any of four serotypes of a virus from the genus flavivirus, called dengue virus. The highest incidence of dengue is seen in Southeast Asia, India and the American tropics (1-4). Dengue affects people of all ages. Severe dengue infections may give rise to many complications such as liver failure, 
disseminated intravascular coagulation, encephalopathy, myocarditis, acute renal failure and haemolytic uraemic syndrome (5).

Although shock in DHF/DSS has been attributed largely to decreased intravascular volume due to capillary leakage of plasma into the interstitial space, a few recent studies have reported that it may be due to cardiac involvement. Acute reversible myocarditis has been reported in patients with dengue infections (6-9). ST segment and $\mathrm{T}$ wave changes in the electrocardiogram together with low ejection fraction and global hypokinesia on radionuclide ventriculography have been found. Thus Dengue fever is not only a serious illness it is emerging as a public health problem, so the need for the study.

In view of the increasing incidence of dengue fever as well as the rising morbidity and mortality due to this, the study of both the subclinical and clinical cardiac manifestations in dengue via clinical examination, cardiac biomarkers, ECG and ECHO cardiography was undertaken

The increase in capillary permeability that occurs in some patients, and can cause intravascular hypovolaemia and shock, is the best known cardiovascular complication associated with dengue.

Additionally, various specific cardiac manifestations have been described, ranging from rare fulminant myocarditis to morecommon associations with functional myocardial impairment and arrhythmias (912). Myocarditis has now been included in the definition of severe dengue adopted in the 2009 WHO revised classification, but the true incidence of myocarditis remains unknown owing to the lack of screening in most countries where DENV is endemic (13-15).

In the past 2 decades, the critical role of myocardial impairment in the development of septic shock has become clear, distinct from cardiovascular compromise caused by reduced preload and systemic vascular resistance. Myocardial impairment is possibly mediated by circulating myocardial depressant factors.

By contrast, the contribution of cardiac dysfunction to haemodynamic compromise in DSS remains to be adequately defined.

The main difficulty in describing the manifestations and frequency of cardiac involvement in dengue is the lack of clear criteria to define cardiac involvement.

Cardiac manifestations of dengue include functional myocardial impairment, arrhythmias, and myocarditis, which can occur through a number of mechanisms.

The wide clinical presentation of, and difficulties in diagnosing, myocarditis make the incidence difficult to quantify.

\section{Aims and Objectives}

To determine the clinical profile of Dengue patients in the study and to Study the cardiac manifestations in patients with dengue fever.

\section{Materials and Methods}

\section{Study site and study population}

The study is planned to be conducted in the Department of General Medicine, Karnataka Institute of Medical Sciences, Hubli, Karnataka

\section{Inclusion criteria}

Dengue fever cases aged more than 18 years attending at KIMS Hospital, Hubli.

Dengue fever cases confirmed by NS1Ag test or both NS1Ag and IgM, IgG positive cases. 


\section{Exclusion criteria}

Patients with previous history of any cardiac illness.

Admission ECG suggestive of old MI.

Medication affecting the heart rate.

Those who doesn't give consent for study

Study design

This is a hospital based Observational study

\section{Study period}

$1 \frac{1}{2}$ year ( $1^{\text {st }}$ March 2017 to August 2018)

\section{Sample size}

Universal Sample size was taken in the study. I.e. all the cases of Dengue Fever admitted to KIMS Hospital, Hubli for the period of $1 \frac{1 / 2}{2}$ year.

\section{Sampling method}

Purposive sampling method was used to recruit patients as and when admitted to Hospital.

\section{Data collection}

This study was a hospital based study conducted in Karnataka Institute of Medical Sciences, Hubli. All the cases which satisfy the inclusion criteria were included in the study. Informed consent was taken and the clinical and laboratory parameters were recorded in predesigned data sheet. Diagnosis and management were done according to WHO guidelines. Serological tests for detection of IgM dengue antibodies and NS1 antigen was done. All the subjects were subjects for laboratory investigations.
The following investigations will be done in all case

Complete hemogram

Platelet count

Antigen test

Serology for dengue IgM, IgG, NS1 antigen

ECG

2D Echocardiography

\section{Statistical analysis}

Data was entered into Microsoft excel data sheet and was analyzed using SPSS 22 version software. Categorical data was represented in the form of Frequencies and proportions. Chisquare test was used as test of significance for qualitative data. Continuous data was represented as mean and standard deviation.

\section{Results and Discussion}

In the study majority $36 \%$ were in the age group 20 to 29 years, followed by $<20$ years $(22 \%)$ and others as shown in table 1 . Mean age of subjects was $30.32 \pm 13.66$ years.

In the study $59 \%$ were males and $41 \%$ were females (Table 2).

In the study $100 \%$ presented with fever, $20 \%$ had associated headache, 4\% had vomiting, $1 \%$ had chills, cough, giddiness and pain abdomen respectively and 2\% had Myalgia. In the study $8 \%$ had Bradycardia and 20\% had tachycardia. Mean Pulse rate was $90.64 \pm$ 13.96 bpm (Table 3).

In the study according to SBP, 6\% had Hypotension and as per DBP, 6\% had hypotension and $1 \%$ had hypertension. 
Mean SBP was $111.7 \pm 10.13 \mathrm{mmhg}$ and mean DBP was $72.92 \pm 8.36 \mathrm{mmhg}$ (Table 4 and 5).

In the study $67 \%$ had no rashes, $24 \%$ had Petechial rashes, $4 \%$ had Ecchymosis (Table 6).

Petechie, 3\% had Gum Bleeding, 1\% had Bleeding in Oral cavity and Subconjuctival Hemorrhage respectively.

In the study $50 \%$ were NS1 positive, $20 \%$ were $\operatorname{IgM}$ positive, $12 \%$ were $\operatorname{IgG}$ Positive, $8 \%$ were $\operatorname{IgM}$ and $\operatorname{IgG}$ positive, $7 \%$ were $\operatorname{IgM}$ and NS1 Positive, 2\% were NS1 and IgG Positive and $1 \%$ were $\mathrm{IgG}$, IgM and NS1 Positive (Table 7).
In the study $31 \%$ had $\mathrm{Hb}<12 \mathrm{gm} \%$ and $69 \%$ had $\mathrm{Hb}>12 \mathrm{gm} \%$. Mean $\mathrm{Hb}$ was $12.68 \pm 2.12$ gm $\%$. In the study $34 \%$ had Total count $<4000$ and $5 \%$ had Total count $>11000$. Mean Total count was 5315.1 \pm 2771.24 (Table 8).

In the study $26 \%$ had platelet count $<20000$, $32 \%$ had 20000 to $50000,18 \%$ had 51000 to 100000 and $24 \%$ had platelet count $>100000$. Mean platelet count was $58648 \pm 48496.45$ (Table 9 and 10).

In the study $18 \%$ were positive for Troponin I and $82 \%$ were negative for Troponin I. In the study $28 \%$ had CK-MB $<25$ and $72 \%$ had CKMB >25. Mean CK-MB was $85.99 \pm 75.73$ (Table 11 and 12).

Table.1 Age distribution in the study

\begin{tabular}{|l|l|c|c|}
\hline \multicolumn{1}{|c|}{ Age } & Count & $\%$ \\
\cline { 2 - 4 } & 20 years & 22 & $22.0 \%$ \\
\cline { 2 - 4 } & 30 29 years 39 years & 36 & $36.0 \%$ \\
\hline & 40 to 49 years & 19 & $19.0 \%$ \\
\cline { 2 - 4 } & $>50$ years & 12 & $12.0 \%$ \\
\hline & Total & 11 & $11.0 \%$ \\
\hline
\end{tabular}

Table.2 Sex distribution of subjects

\begin{tabular}{|l|l|c|c|}
\hline \multicolumn{1}{|c|}{ Sex } & Female & Count & $\%$ \\
\cline { 2 - 4 } & Male & 41 & $41.0 \%$ \\
\cline { 2 - 4 } & Total & 59 & $59.0 \%$ \\
\hline
\end{tabular}

Table.3 Symptoms among subjects

\begin{tabular}{|l|l|c|c|}
\hline \multicolumn{1}{|c|}{ Fever } & Present & Count & $\%$ \\
\hline \multirow{2}{*}{ Headache } & Absent & 100 & $100.0 \%$ \\
\hline & Present & 40 & $40.0 \%$ \\
\hline \multirow{3}{*}{ Others } & Absent & 60 & $60.0 \%$ \\
\cline { 2 - 4 } & Present & 94 & $94.0 \%$ \\
\hline & Chills & 6 & $6.0 \%$ \\
\cline { 2 - 4 } & Cough & 1 & $1.0 \%$ \\
\cline { 2 - 4 } & Giddiness & 1 & $1.0 \%$ \\
\cline { 2 - 4 } & Myalgia & 1 & $1.0 \%$ \\
\hline & Nil & 4 & $4.0 \%$ \\
\cline { 2 - 4 } & Pain Abdomen & 89 & $89.0 \%$ \\
\hline
\end{tabular}


Table.4 Pulse rate among subjects

\begin{tabular}{|l|l|c|c|}
\hline \multicolumn{1}{|c|}{ Pulse Rate } & Count & $\%$ \\
\cline { 2 - 4 } & Noradycardia & 8 & $8.0 \%$ \\
\cline { 2 - 4 } & Tachycardia & 72 & $72.0 \%$ \\
\hline
\end{tabular}

Table.5 Blood pressure among subjects

\begin{tabular}{|l|l|c|c|}
\hline \multirow{5}{*}{ SBP } & Hypotension & Count & $\%$ \\
\cline { 2 - 4 } & Normal BP & 6 & $6.0 \%$ \\
\hline \multirow{2}{*}{ DBP } & Hypotension & 94 & $94.0 \%$ \\
\cline { 2 - 4 } & Normal BP & 6 & $6.0 \%$ \\
\cline { 2 - 4 } & Hypertension & 93 & $93.0 \%$ \\
\hline
\end{tabular}

Table.6 Rashes among subjects

\begin{tabular}{|l|l|c|c|}
\hline \multirow{3}{*}{ Rashes+ } & Nil & Count & $\%$ \\
\cline { 2 - 4 } & Petechial rashes + & 67 & $67.0 \%$ \\
\hline Ecchymosis,Petechie+ & 24 & $24.0 \%$ \\
\hline & Gum Bleeding & 4 & $4.0 \%$ \\
\cline { 2 - 4 } & Bleeding in Oral cavity & 3 & $3.0 \%$ \\
\cline { 2 - 4 } & Subconjuctival Hemorrhage & 1 & $1.0 \%$ \\
\hline
\end{tabular}

Table.7 Dengue serology among subjects

\begin{tabular}{|l|l|c|c|}
\hline \multirow{2}{*}{ Dengue Test } & NS1 Positive & Count & $\%$ \\
\cline { 2 - 4 } & IgM positive & 50 & $50.0 \%$ \\
\hline & IgG Positive & 20 & $20.0 \%$ \\
\hline & IgM and IgG positive & 12 & $12.0 \%$ \\
\hline & IgM and NS1 Positive & 8 & $8.0 \%$ \\
\hline & NS1 and IgG Positive & 7 & $7.0 \%$ \\
\hline IgG, IgM and NS1 Positive & 2 & $2.0 \%$ \\
\hline & Total & 1 & $1.0 \%$ \\
\hline
\end{tabular}

Table.8 Hb distribution among subjects

\begin{tabular}{|l|l|c|c|}
\hline \multicolumn{1}{|c|}{} & Count & $\%$ \\
\hline \multirow{2}{*}{$\mathrm{Hb}$} & $<12 \mathrm{gm} \%$ & 31 & $31.0 \%$ \\
\hline & $>12 \mathrm{gm} \%$ & 69 & $69.0 \%$ \\
\hline
\end{tabular}


Int.J.Curr.Microbiol.App.Sci (2019) 8(7): 636-644

Table.9 Total count distribution among subjects

\begin{tabular}{|l|l|c|c|}
\hline \multirow{3}{*}{ Total Count } & \multicolumn{1}{|c|}{ Count } & $\%$ \\
\cline { 2 - 4 } & 40000 & 34 & $34.0 \%$ \\
\cline { 2 - 4 } & $>11000$ & 61 & $61.0 \%$ \\
\hline
\end{tabular}

Table.10 Platelet Count Distribution among subjects

\begin{tabular}{|c|c|c|c|}
\hline \multirow{5}{*}{ Platelet count } & & Count & $\%$ \\
\hline & $<20000$ & 26 & $26.0 \%$ \\
\hline & 20000 to 50000 & 32 & $32.0 \%$ \\
\hline & 51000 to 100000 & 18 & $18.0 \%$ \\
\hline & $>100000$ & 24 & $24.0 \%$ \\
\hline
\end{tabular}

Table.11 Troponin levels distribution among subjects

\begin{tabular}{|c|c|c|c|}
\hline & & Count & $\%$ \\
\hline \multirow[t]{3}{*}{ Troponin } & Positive (>0.017) & 18 & $18.0 \%$ \\
\hline & Negative $(<0.017)$ & 82 & $82.0 \%$ \\
\hline & Total & 100 & $100.0 \%$ \\
\hline
\end{tabular}

Table.12 CK-MB distribution among subjects

\begin{tabular}{|l|l|c|c|}
\hline \multicolumn{1}{|c|}{ CK-MB } & $<25$ & Count & $\%$ \\
\cline { 2 - 4 } & $>25$ & 12 & $28.0 \%$ \\
\hline
\end{tabular}

Table.13 ECG findings among subjects

\begin{tabular}{|l|l|c|c|}
\hline \multirow{4}{*}{ ECG } & Normal & Count & $\%$ \\
\cline { 2 - 4 } & Sinus Bradycardia & 56 & $56.0 \%$ \\
\cline { 2 - 4 } & Sinus Tachycardia & 15 & $15.0 \%$ \\
\cline { 2 - 4 } & T wave changes & 9 & $9.0 \%$ \\
\cline { 2 - 4 } & ST Changes & 10 & $10.0 \%$ \\
\hline & Sinus Bradycardia with T Wave Changes & 2 & $3.0 \%$ \\
\cline { 2 - 4 } & Sinus Tachycardia with T wave changes & 2 & $2.0 \%$ \\
\cline { 2 - 4 } & LVH & 1 & $2.0 \%$ \\
\cline { 2 - 4 } & Abnormal Rhythm & 2 & $1.0 \%$ \\
\hline
\end{tabular}


Table.14 ECHO findings among subjects

\begin{tabular}{|l|l|c|c|}
\hline \multirow{3}{*}{ ECHO Findings } & Normal & Count & $\%$ \\
\cline { 2 - 4 } & Anterior Wall Hypokinesia & 85 & $85.0 \%$ \\
\hline & Mild PAH and Mild TR & 6 & $6.0 \%$ \\
\hline & Mild PAH, Mild TR, Hypokinesia Ant.wall & 1 & $1.0 \%$ \\
\hline & LVH & 4 & $4.0 \%$ \\
\hline & DCM Secondary to Dengue Myocarditis & 1 & $1.0 \%$ \\
\hline & Mild AML Prolapse & 2 & $2.0 \%$ \\
\hline
\end{tabular}

Table.15 LFT findings among subjects

\begin{tabular}{|l|l|c|c|}
\hline \multicolumn{1}{|c|}{} & Count & $\%$ \\
\hline \multirow{2}{*}{ LFT } & Abnormal & 29 & $29.0 \%$ \\
\cline { 2 - 4 } & WNL & 71 & $71.0 \%$ \\
\hline
\end{tabular}

Table.16 Renal function tests in study subjects

\begin{tabular}{|l|l|l|c|}
\hline \multirow{2}{*}{} & \multicolumn{2}{|c|}{ Number of Cases } & \multirow{2}{*}{ Total } \\
\cline { 2 - 4 } & Deranged RFT & Normal & \\
\hline Male & 5 & 54 & 59 \\
\hline Female & 3 & 38 & 41 \\
\hline Total & 8 & 92 & 100 \\
\hline
\end{tabular}

In the study $56 \%$ had normal ECG, $15 \%$ had Sinus Bradycardia, $9 \%$ had Sinus Tachycardia, $10 \%$ had $\mathrm{T}$ wave changes, $3 \%$ had ST Changes, 2\% had Sinus Bradycardia with $\mathrm{T}$ Wave Changes, $2 \%$ had Sinus Tachycardia with $\mathrm{T}$ wave changes and $1 \%$ had LVH and 2\% had Abnormal Rhythm (Table 13).

In the study $85 \%$ had normal ECHO, $6 \%$ had Anterior Wall Hypokinesia, 1\% had Mild PAH and Mild TR, Mild MR, Mild PAH, Mild TR, Hypokinesia Ant. wall, LVH, DCM Secondary. To dengue myocarditis and bradycardia, mild AML prolapse respectively (Table 14).

In the study $29 \%$ had abnormal Liver function tests. In the Study subjects: 5 Males and 3
Females had Deranged RFT and 54 Males and 38 Females had Normal RFT (Table 15 and 16).

Cardiac manifestations in dengue virus infection can range from asymptomatic Bradycardia to life threatening myocarditis (16-19). Various studies have quoted several cardiac manifestations of dengue infection viz. sinus Bradycardia, transient AV blocks, transient ventricular arrhythmias, myocarditis, systolic and diastolic dysfunction and pericardial effusion.

Myocardial involvement may be the direct result of dengue virus infection in susceptible individuals or may be due to effects of cytokines / cellular mediators of immune response. 
The present study was done with the aim to determine the clinical profile of Dengue patients and to Study the cardiac manifestations in patients with dengue fever

\section{Cardiac manifestations}

In the present study $56 \%$ had normal ECG and $44 \%$ had abnormal ECG findings, of them 15\% had Sinus Bradycardia, 9\% had Sinus Tachycardia, $10 \%$ had $\mathrm{T}$ wave changes, $3 \%$ had ST Changes, 2\% had Sinus Bradycardia with T Wave Changes, 2\% had Sinus Tachycardia with $\mathrm{T}$ wave changes and $1 \%$ had LVH and 2\% had Abnormal Rhythm.

In the study by Kularatne, $62.5 \%$ of patients had abnormal ECG findings.

In the study by Sheethal et al., the commonest rhythm abnormality noted was sinus bradycardia, found in $32 \%$. Three patients had unexplained sinus tachycardia. In the study by Gupta et al., sinus bradycardia was found in $14.28 \%$, and sinus tachycardia 21.4 percent. AV dissociation with sinus node dysfunction was observed in one patient, which resolved in 24 hours. Kaushik et al., have described atrioventricular dissociation and sino atrial exitblock in a child with dengue fever. Ventricular arrhythmias in the form of ventricular bigeminy, ventricular trigeminy and ventricular tachycardia was noted in one patient each. All these changes reverted back to sinus rhythm in 24 hours. Chuah et al., and Veloso et al., have described transient ventricular arrhythmias as a cardiac manifestation of dengue fever.

In the present study on ECHO, 6\% had Anterior Wall Hypokinesia, 1\% had Mild PAH and Mild TR, Mild MR, Mild PAH, Mild TR, Hypokinesia Anterior wall, LVH, $2 \%$ had DCM Secondary to Dengue Myocarditis And, Mild AML Prolapse Respectively.
In the study by Sheetal et al., Echocardiographic evaluation was done in 18 patients. Three patients were noticed to have Mild pericardial effusion. Echocardiographic evidence of myocarditis was not seen in any patient. In the study by Gupta et al., systolic dysfunction was absent in all patients; mild diastolic dysfunction was present in 14.28 percent. Wiwanitkit et al., have described cases of dengue myocarditis.

In study by Carlos Henrique Miranda 2 patients had reduced LV function, two had LV segmental hypokinesia and one had pericardial effusion

The incidence of cardiac manifestations was present in $44 \%$ of the patients. A wide range of cardiac manifestations was observed in this study. CK-MB and Troponin I at admission were raised in $72 \%$ and $18 \%$ respectively. On ECG, $56 \%$ of the patients had normal rhythm, $15 \%$ had sinus Bradycardia, 9\% had sinus tachycardia, $10 \%$ had $\mathrm{T}$ wave changes, 3\% had ST Changes, $8 \%$ had Sinus Bradycardia with $\mathrm{T}$ Wave Changes, 2\% had Sinus Tachycardia with $\mathrm{T}$ wave changes and $1 \%$ had LVH and $2 \%$ had Abnormal Rhythm. On $2 \mathrm{D}$ ECHO $6 \%$ had Anterior Wall Hypokinesia, 1\% had LVH, and 2\% DCM secondary.to dengue myocarditis.

Hence Transient cardiac abnormality can be an important presentation among patients with Dengue fever and this should guide the treating physician to look for cardiac involvement

\section{References}

1. Chuah SK. Transient ventricular arrhythmia as a cardiac manifestation in dengue haemorrhagic fever--a case report. Singapore Med J 1987; 28:56972.

2. Elenbaas, RM, Elenbaas, JK, Cuddy, 
PG. Evaluating the medical literature, part II: Statistical analysis. Ann Emerg Med. 1983; 12: 610-620.

3. Gaddis, ML, Gaddis, GM. Introduction to biostatistics: Part 4, Statistical inference techniques in hypothesis testing. Ann Emerg Med. 1990; 19: 820-825.

4. Gupta V K, Godpayle A K. Subclinical cardiac involvement in dengue hemorrhagic fever. JIACM 2010; 11(2): 107-11

5. Horta Veloso H, Ferreira Jr.J.A; Braga de Paiva J.M, Faria Honorio, J, Junquiria Belli, AA. Vicenzode Paola A.A. Acute Atrial fibrillation during Dengue Hemorrhagic Fever. Braz $\mathbf{J}$ infect Dis, Vol. 7, 2003, PP. 418-422

6. Horta Veloso H, Ferreira Júnior JA, Braga de Paiva JM, et al., Acute atrial fibrillation during dengue hemorrhagic fever. Braz J Infect Dis 2003; 7:418-22.

7. J M Pelupessy E R Allo, S Jota; Pericardial effusion in dengue haemorrhagic fever. Paediatrica Indonesiana 1989; 29:72-5

8. Kaushik JS, Gupta P, Rajpal S, Bhatt S. Spontaneous resolution of sinoatrial exit block and atrioventricular dissociation in a child with dengue fever. Singapore Med J 2010; 51:e146-8.

9. Kularatne SA, Pathirage MM, Kumarasiri PV, Gunasena S, Mahindawanse SCardiac complications of a dengue fever outbreak in Sri Lanka. Trans R Soc Trop Med Hyg. 2007; 101(8): 804-8.

10. Lee, C. H., Teo, C. and Low, A. F. Fulminant dengue myocarditis masquerading as acute myocardial infarction. Int. J. Cardiol 2009; 136: 6971.

11. Merx, M. W. \& Weber, C. Sepsis and the heart. Circulation 116, 793-802 (2007).

12. Miranda C.H, Borges Mde. C, Matsuno A.K et al., Clinical Infectious diseases journal, 2013; 57(6): 812-9.

13. Nagaratnam N, Siripala K, de Silva N. Arbovirus (dengue type) as a cause of acute myocarditis and pericarditis. $\mathrm{Br}$ Heart J 1973; 35:204-6.

14. Patra P. Sample size in clinical research, the number we need. Int J Med Sci Public Health. 2012; 1:5-9.

15. Pulido, J. N. et al., Clinical spectrum, frequency, and significance of myocardial dysfunction in severe sepsis and septic shock. Mayo Clin. Proc. 87, 620-628 (2012).

16. Salgado DM, Rodríguez JA, Garzón M, Cifuentes G, Ibarra M, Vega MR, Castro D. Clinical and epidemiological characterisation of dengue haemorrhagic fever in Neiva, Colombia, 2004. Rev Salud Publica (Bogota) 2007; 9:53-63.

17. Sunder Rao P S S, Richard J (2006): An Introduction to Biostatistics, A manual for students in health sciences, New Delhi: Prentice hall of India. 4th edition, 86-160.

18. Wiwanikit; Dengue Cardiac Infection, A Brief Review; Acta Cardiol Sin 2008; 24:226

19. Yacoub, S. et al., Cardiac function in Vietnamese patients with different dengue severity grades. Crit. Care Med 2012; 40: 477-483.

\section{How to cite this article:}

Arati Kalakutakar, H. Suresh and Ashok, G. 2019. Study of Cardiac Manifestations in Dengue Fever. Int.J.Curr.Microbiol.App.Sci. 8(07): 636-644.

doi: https://doi.org/10.20546/ijcmas.2019.807.078 